\title{
Flexibility modeling of reinforced concrete concentric frame joints
}

\section{Modelação da flexibilidade de nós concêntricos de pórticos em concreto armado}
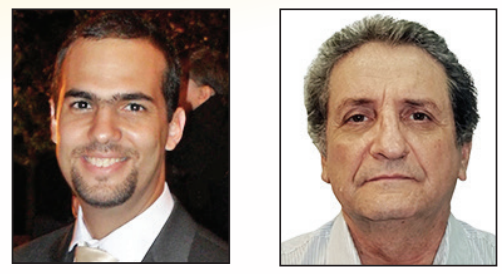

S. J. P. J. MARQUES FILHO a sergiopriorifilho@hotmail.com

B. HOROWITZ b horowitz@ufpe.br

\begin{abstract}
The intersections between beams and columns in a reinforced concrete building structure are called frame joints. It is a region with significant bending stiffness but subjected to large shear stresses. Appropriate modeling of the flexibility of reinforced concrete frames is essential to its design, in service limit states as well as in ultimate limit states. It has been shown, theoretically as well as experimentally, that the influence of joint flexibility may account for $20 \%$ of total structural lateral displacement. Models using only bar elements and rotational springs are proposed to consider the joint flexibility in linear analyses of building structures. In order to validate the proposed model, comparisons with experimental results found in the literature are made. Finally, the results of second order analyses using the proposed model are compared with those obtained by finite elements.
\end{abstract}

Keywords: reinforced concrete, frame joint, building structural analysis.

\section{Resumo}

A zona de interseção de vigas e pilares em estruturas de edifícios é chamada nó de pórtico. Trata-se de região com rigidez significativa à flexão, porém sujeita a grandes solicitações de cisalhamento. A apropriada modelação da flexibilidade de pórticos é essencial ao seu dimensionamento, tanto nos estados limites de serviço quanto nos estados limites últimos. Foi verificado tanto teoricamente quanto experimentalmente que a influência da flexibilidade dos nós pode alcançar $20 \%$ do deslocamento total da estrutura. Modelo utilizando apenas elementos de barras e molas é proposto para levar em consideração a flexibilidade dos nós na análise de estruturas de edifícios correntes. De forma a validar o modelo proposto, são realizadas comparações com resultados experimentais encontrados na literatura. Por fim, os resultados da análise considerando os efeitos de segunda ordem utilizando o modelo proposto são comparados com aqueles obtidos por elementos finitos.

Palavras-chave: concreto armado, nós de pórtico, análise estrutural de edifícios.

\footnotetext{
Departamento de Engenharia Civil, Universidade Federal de Pernambuco, sergiopriorifilho@hotmail.com, Av. Acadêmico Hélio Ramos s/n 50740-530, Recife-PE-Brasil.

b Departamento de Engenharia Civil, Universidade Federal de Pernambuco, horowitz@ufpe.br, Av. Acadêmico Hélio Ramos s/n, 50740-530, Recife-PE-Brasil.
} 


\section{Introduction}

The zone of overlapping of beams and columns in reinforced concrete buildings is called frame joint. This region has significant bending stiffness but is subjected to large shear stresses. In building framed structures subjected to lateral loading, zero moment can be considered at mid-height of columns and at mid-span of beams. Thus, the subassemblage highlighted in Figure 1 can be used to represent the interaction between beams and columns of a frame.

This work studies the cases where the axes of beams intersect the axes of framed columns. Two types of joints are studied: complete joints, whose beams and columns have the same width, and concentric joints, where the column width is larger than the beam width, as illustrated in Figure 3. As shown in Figure 2 the joints are grouped according to their geometry as interior cross-type joint, TLateral exterior joint, T-Top exterior joint, and L-type joint.

The main objective of this study is to propose a simplified model of ready numerical implementation that uses only bars and spring elements to take into account the flexibility of joint regions which may account for $20 \%$ of total structural lateral displacement, as demonstrated by the experimental results of Shin and LaFave [1]. To simplify the development of the proposed approximate model the restraining effects of slabs and transverse beams are neglected. This is a conservative assumption since it tends to decrease joint stiffness. These additional effects will be the focus of the next phases of the present research. Unfortunately very few experimental results are reported in the literature of joints including those restraining members.

\section{Figure 1 - Bending moment diagram of a laterally loaded frame}

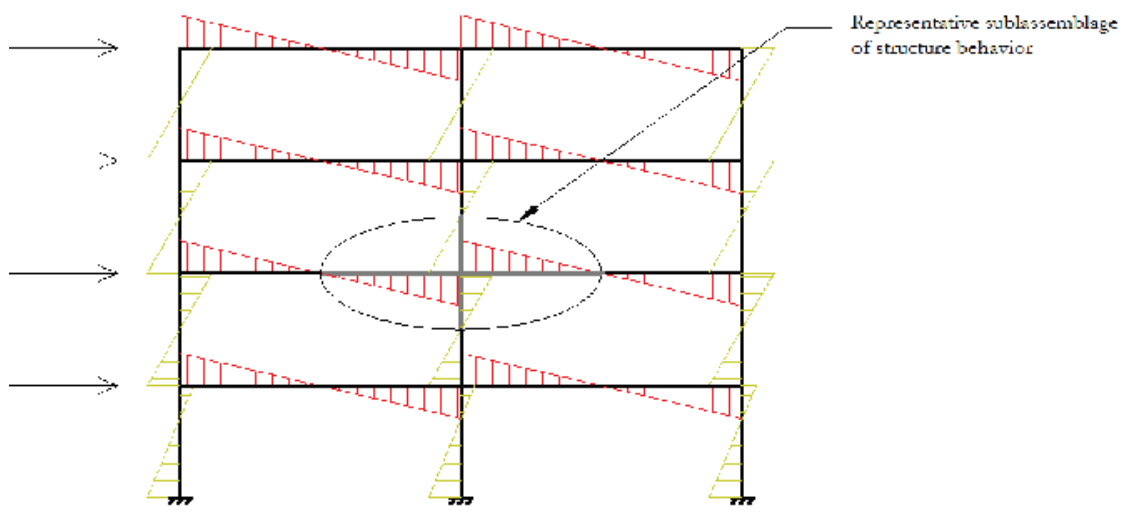

Figure 2 - Building subjected to lateral loads with all different joint types: (a) L-type joint; (b) T-Top exterior joint; (c) Cross-Type interior joint; (d) T-Lateral exterior joint

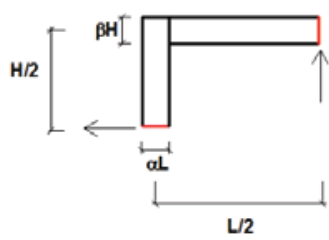

(a)

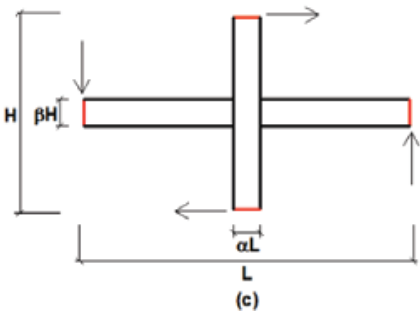

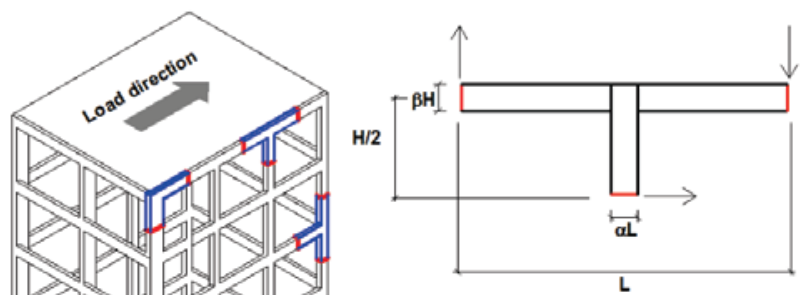

(b)

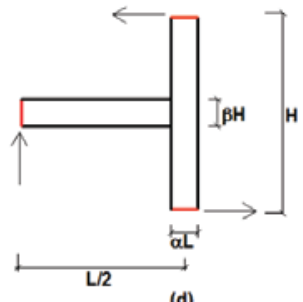




\section{Figure 3 - Elevation and plan view of the example substructure (in $\mathrm{cm}$ )}

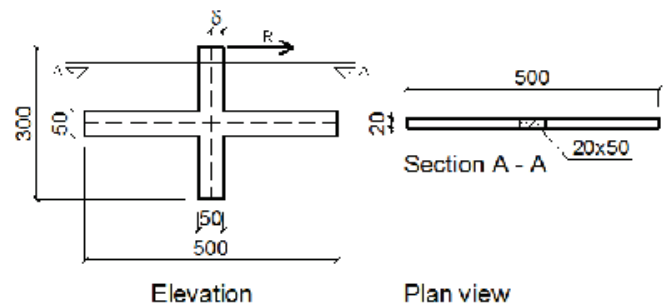

(a) Complete joint

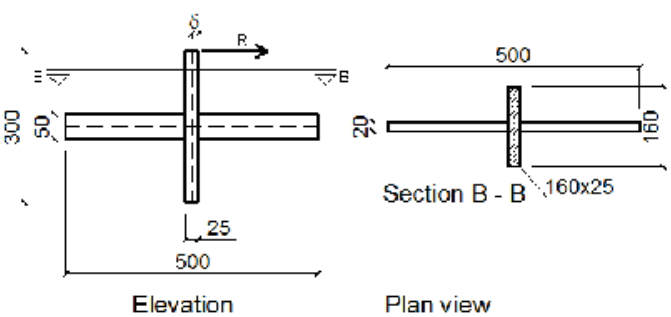

(b) Concentric jaint

Three-dimensional finite element models of beam/column subassemblages are submitted to unit displacements at one of the column end sections, and comparisons are made between the resulting reactions against those obtained using the proposed model. As a result of this study required parameters of the model are adjusted. Only elastic analysis is considered since this is the usual approach for nonseismic design of building structures, where second order effects are directly or approximately taken into account. In order to validate the adopted parameter values, comparisons are made between the predicted values of displacements against experimental subassemblage results for drift values compatible with the NBR-6118 code [2] limits for service lateral displacement. In order to assess the accuracy of the proposed simplified model, second order analyses incorporating the model were performed on several multistory building frames. Obtained results are compared with those of second order, three-dimensional, finite element analyses.

\section{Impact of joint flexibility}

In order to gain an initial insight on the impact of joint flexibility on structural behavior consider the illustrative example of Figure 3 where two interior joint subassemblages are shown. The first is a complete type joint, consisting of beams with $5 \mathrm{~m}$ span and a $3 \mathrm{~m}$ high column. Both beams and columns have a $20 \mathrm{~cm}$ by $50 \mathrm{~cm}$ rectangular cross-section. The second joint is concentric and differs from the first only in the cross-section of the column which is $160 \mathrm{~cm}$ by $25 \mathrm{~cm}$. Note that both columns have the same moment of inertia in the plane of bending. In both subassemblages horizontal displacement of the bottom section of the column as well as the vertical displacements of the end sections of the beam are prevented. The goal is to evaluate the required horizontal force applied to top of the column which produces a $1 \mathrm{~cm}$ horizontal displacement. The modulus of elasticity of the concrete is $20,6 \mathrm{GPa}$ and Poisson's ratio is 0,2 .

Initially consider as a basis the finite elements model of the first example, shown in Figure 4(a). This model uses quadratic hexahedron elements having twenty nodes with reduced integration implemented in the commercial code ABAQUS [3]. Concrete is modeled as a linear elastic homogeneous material. The discretization mesh follows the guidance given in Reference [4] for bending problems which suggests at least two elements through the width and shows excellent agreement with beam theory using four elements through the height, as well as experience gained throughout the present research. These techniques are used for the finite element models in the remainder of this study.

For the finite element model of Figure 4(a) the value of the reaction force at the top section of the column corresponding to the imposed unit displacement is $81,5 \mathrm{kN}$. Consider now the model shown in Figure 4(b) consisting only of bar elements where rigid links are specified for both beams and columns in the interior of the joint. In this case, the necessary force is $100 \mathrm{kN}$. If no rigid links

\section{Figure 4 - (a) Finite elements model; (b) Bars model with rigid links in the joint region}

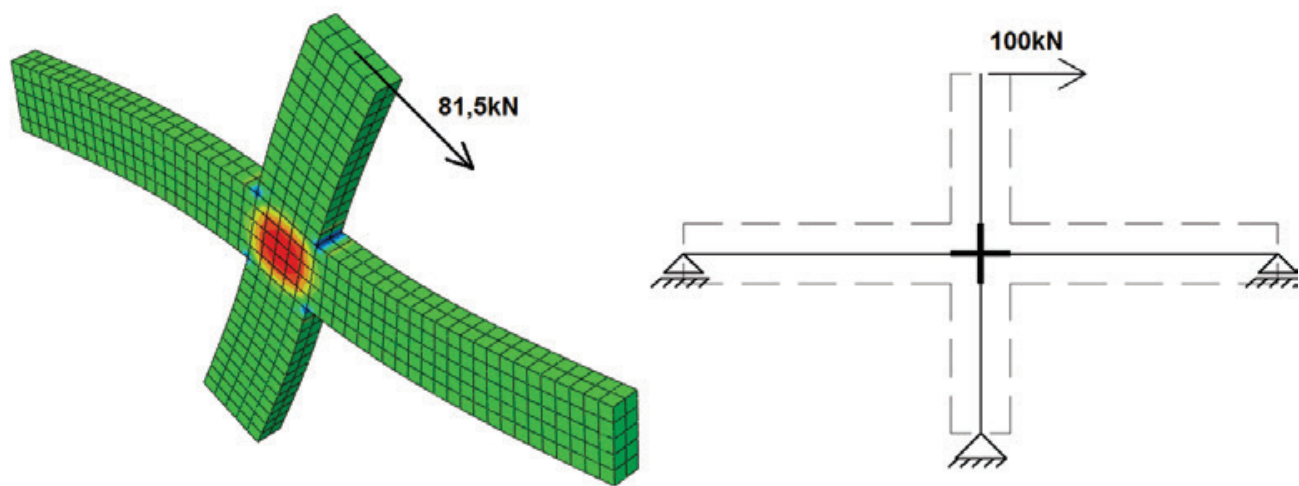




\section{Figure 5 - (a) Joint deformed configuration; (b) Shear and normal stresses}
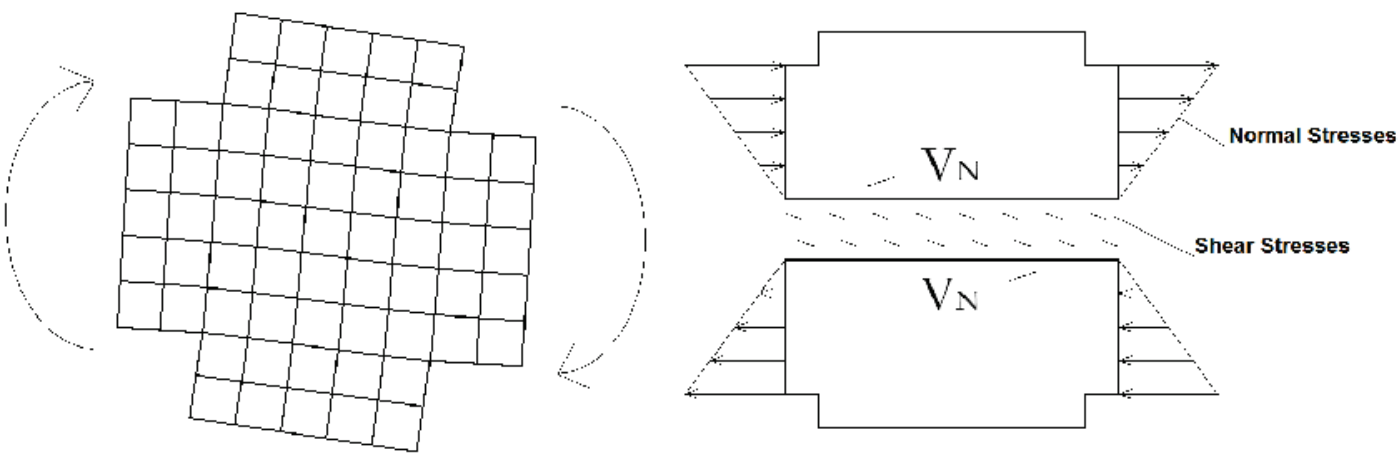

are specified, with all bars having constant properties throughout their lengths, completely neglecting the stiffness of the joint region, the corresponding force would be $68,3 \mathrm{kN}$. Computing the ratios of those different values of required forces to the finite element result one concludes that the stiffness of the subassemblage is either overestimated by $23 \%$ or underestimated by $16 \%$.

Figure 4(a) shows color-filled contours of shear stresses. It can be seen that there exists a high concentration of shear stress in the joint zone. These stresses result from the combined action of normal stresses due to bending moments of same sense applied by beams and columns to the joint. Figure 5(a) shows a representation of the moments applied by the beams to the joint. Figure 5 (b) shows the normal stresses resulting from the applied bending moments and the required shear stresses inside the joint to maintain equilibrium. Joint shown in Figure 5(a) also suggests that the largest contribution to joint deformation is due to shear distortion, and not bending in the interior of the joint

For the second case, shown in Figure 3(b), of the illustrative ex- ample observe from Figure 6(a) that the reaction obtained from the finite element model is $74 \mathrm{kN}$, corresponding to an imposed displacement of $1 \mathrm{~cm}$ at the top of the column. For a bar model with rigid links inside the joint the reaction force is $92,1 \mathrm{kN}$. Figure $6(\mathrm{~b})$, which shows a section through the symmetry plane of the joint, depicts again the concentration of shear stresses inside the joint. If no rigid links are specified the required force is $69,7 \mathrm{kN}$.

Despite beams and columns having the same moment of inertia, the joint of the second example has less stiffness than that of the first example. Among various factors, one of the largest contributors to the increase of the flexibility of the connection is the additional torsional deformation that exists in the column. This subject will be discussed in detail in section 4.1.

From the above discussion it can be concluded that in usual situations, errors in joint modeling can result in lateral displacement errors in the order of 20\%. Experimental results from Shin and LaFave [3] show that joint flexibility contribute with $24 \%$ of total lateral displacement for drifts of $1 \%$ of story height and $53 \%$ for drifts of $6 \%$ of story height.

Figure 6 - (a) Interior frame joint substructure; (b) Concentration of shear stress inside the frame joint

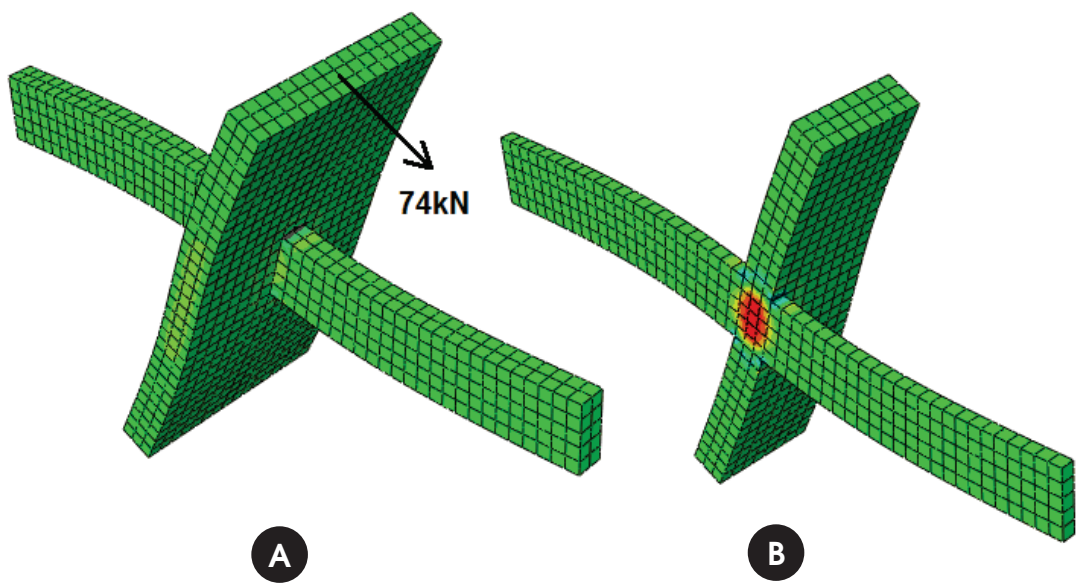




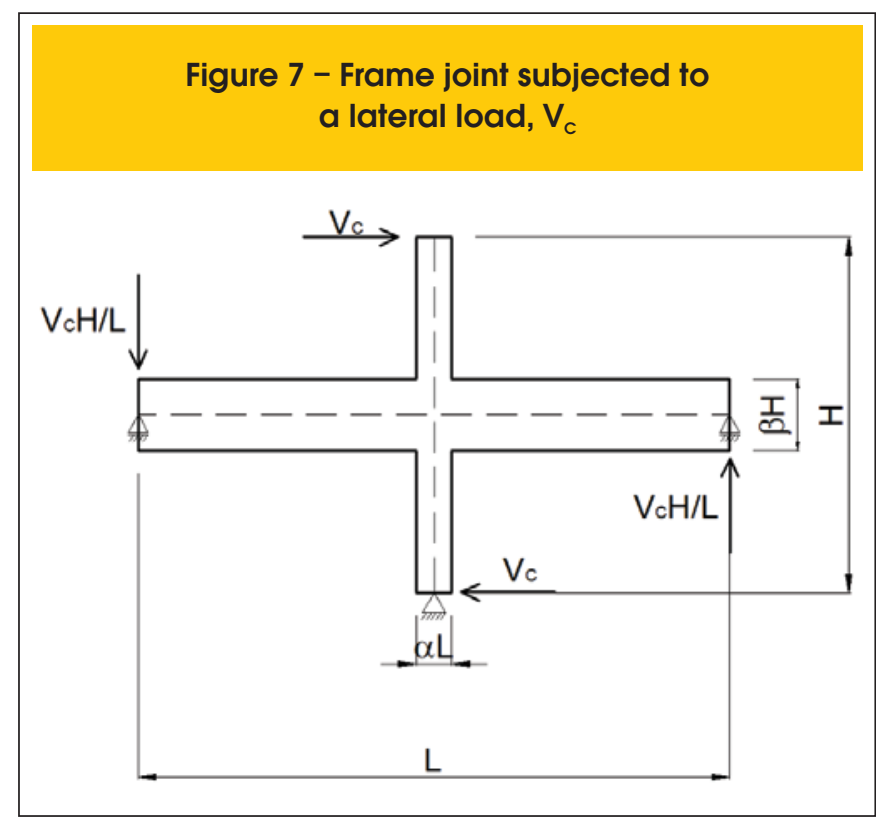

It can then be concluded that the contribution of joint flexibility to displacements is significant and must be taken into account in checking the limit state of excessive lateral displacements of building frames. In ultimate limit states second order global effects are also directly affected by joint flexibility, whose capacity to absorb the shear force must be checked.

\section{Complete joints}

Consider again the model shown in Figure 4(a), which corresponds to the complete joint of Figure 3(a). The top section displacement is due to contributions of beams, columns, and joint deformations. The deformation in the joint zone has normal, bending, and shear components. The most significant part is due to shear distortion that will be discussed in more detail in order to develop of an approximate expression of its stiffness where the important factors are included, with the correct power. In a second step the approximated expression is adjusted as a result of the conducted parametric study.

\subsection{Flexibility of complete frame joints}

Consider the subassemblage in Figure 7 subjected to a horizontal loading, $V_{c}$, applied to the top of the column. Different modeling alternatives for joint flexibility of steel frames made of wide-flange sections are discussed by Charney and Downs [5]. They show that if on equates the lever arm between tension and compression stress resultants to the beam depth, the horizontal shear at the center of the joint, $V_{N}$ (see Figure $5(\mathrm{~b})$ ), is given by:

$$
V_{N}=\frac{V_{C}(1-\alpha-\beta)}{\beta}
$$

Where $\alpha$ is the ratio of column width to beam span, $L$. The ratio of beam depth to story height, $H$, is equal to $\beta$, as depicted in Figure 7 . The average shear stress is given by:

$$
\tau_{N}=\frac{V_{N}}{t \alpha L}=\frac{V_{N} \beta H}{t \alpha L \beta H}=\frac{V_{N} \beta H}{\nabla_{N}}
$$

Where: $t$ =joint thickness and $\nabla_{N}=$ volume of joint region.

Figure 8 - (a) Adjusted rigid links model; (b) scissors model

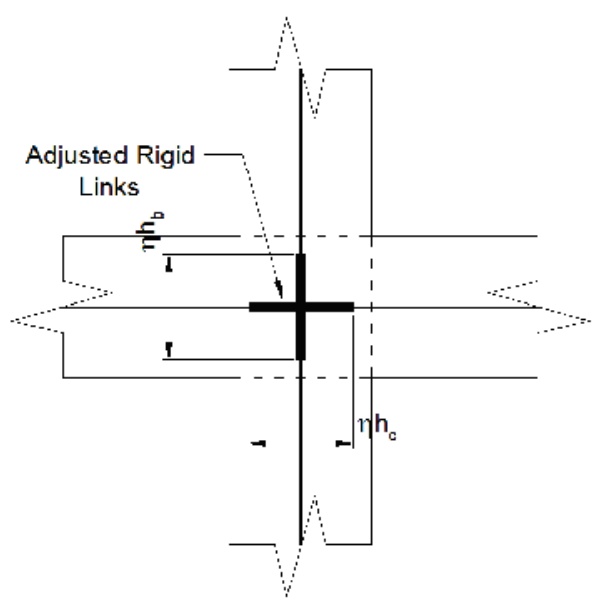

A

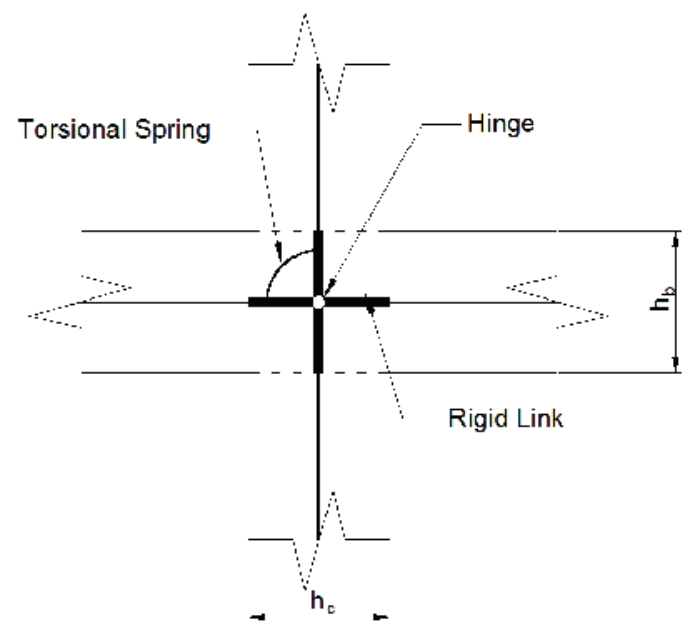

B 
Substituting $V_{N}$ in Equation (2) for its value in Equation (1), on gets:

$$
\tau_{N}=\frac{V_{N} H(1-\alpha-\beta)}{\nabla_{N}}
$$

Using the unit dummy load method for computing the horizontal displacement of the upper section of the column one has that the shear stress corresponding to $V_{C}=1$ is:

$$
\tau_{1}=\frac{H(1-\alpha-\beta)}{\nabla_{N}}
$$

Thus, the contribution, $\Delta_{N}$, to the horizontal displacement at the top of the column due to shear stress at the joint is given by:

$$
\Delta_{N}=\int_{\nabla_{N}} \frac{\tau_{N} \tau_{1}}{G} d V=\frac{V_{C} H^{2}(1-\alpha-\beta)^{2}}{G \nabla_{N}}
$$

Where $G$ is the transverse modulus of elasticity of concrete.

The two different alternatives for the modeling of joint flexibility discussed in the following sections are:

Adjusted rigid links model.

Scissors model.

\subsection{Adjusted rigid links model}

As previously discussed, the simple adoption of rigid links in the interior of the beam/column joint results in stiffness overestimation. A frequently adopted alternative is to adjust the length of the rigid links by multiplying by a factor $\eta \leq 1$, so as to shorten them, as can be seen in Figure 8(a). This model implicitly assumes that flexibility is due to bending deformation inside the joint.

Parametric study conducted by Horowitz and Marques[6] shows that $\eta$ values varies between 0.44 and 0.75 , and is highly dependent on the ratio of beam to column section heights, thus not being convenient for general use. This finding is corroborated by the recent study of Birely et al [7] where the adjusted rigid links model is used for seismic design and evaluation, based on a data base of experimental results including 45 cross type interior joints. Depending on frame effective stiffness approach and joint reinforcement design criterion $\eta$ values vary all the way from 0 to 1 . Therefore this model is not pursued any further in this study

\subsection{Scissors model}

Consider the model shown in Figure 8(b) consisting of rigid links at the ends of the members inside the joint, a hinge, and a torsional spring. The stiffness of the torsional spring represents the shear stiffness of the joint. This simple model was proposed by Krawinkler and Mohasseb [8] to consider the effect of panel zones of steel moment-resisting frames.
For the scissors model the moment in the spring is $V_{c} H$. The displacement at the top of the column only due to the flexibility of the joint region is given by:

$$
\Delta_{N}=\frac{V_{C} H}{K_{N T}} H
$$

Where: $K_{N T}=$ stiffness of the spring of the scissors model. Equating the displacements given by Equations (5) and (6):

$$
K_{N T}=\frac{G \nabla_{N}}{(1-\alpha-\beta)^{2}}
$$

Comparative studies of steel interior joint subassemblages with experimental results and full planar frames, including P-Delta effects, reported in Charney and Downs [5] shows that the scissors model is effective for steel building structures in general.

\subsection{Parametric study of complete frame joints}

Since simplifying assumptions were adopted regarding the distribution of shear stresses and lever arm of the normal stress resultants, a correction factor, $\gamma$, is needed in Equation (7). The resulting expression for the torsional spring is then given by:

$$
K_{\text {complete }}=\gamma \frac{G \nabla_{N}}{(1-\alpha-\beta)^{2}}
$$

A parametric study was conducted keeping constant the width of all members at $20 \mathrm{~cm}$ and beam spans of $5 \mathrm{~m}$ between col-

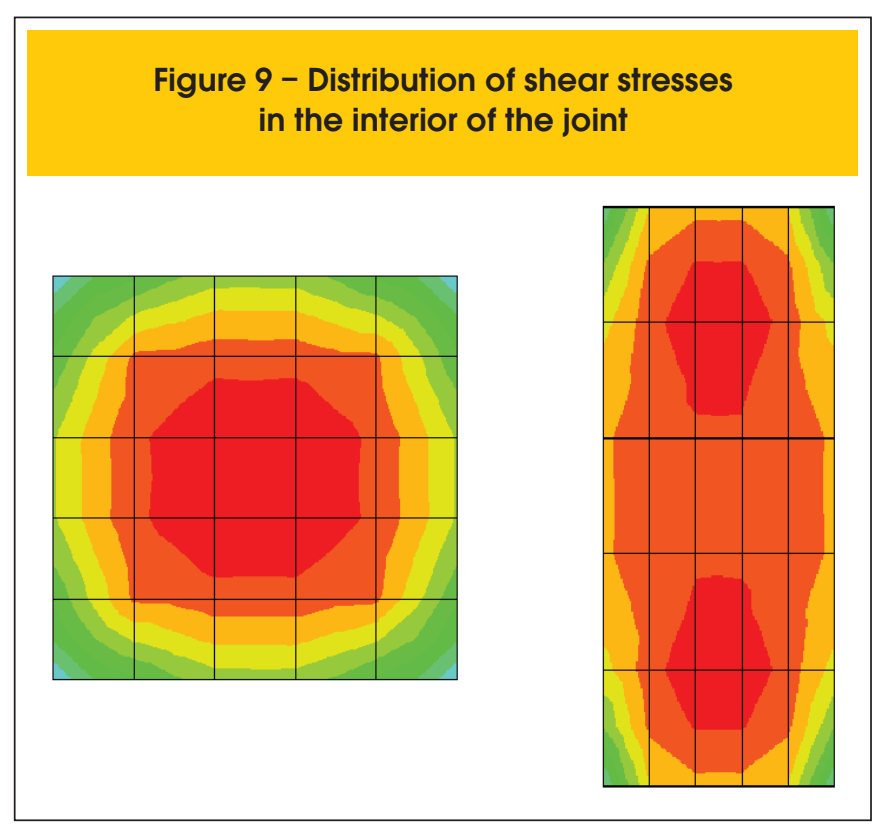



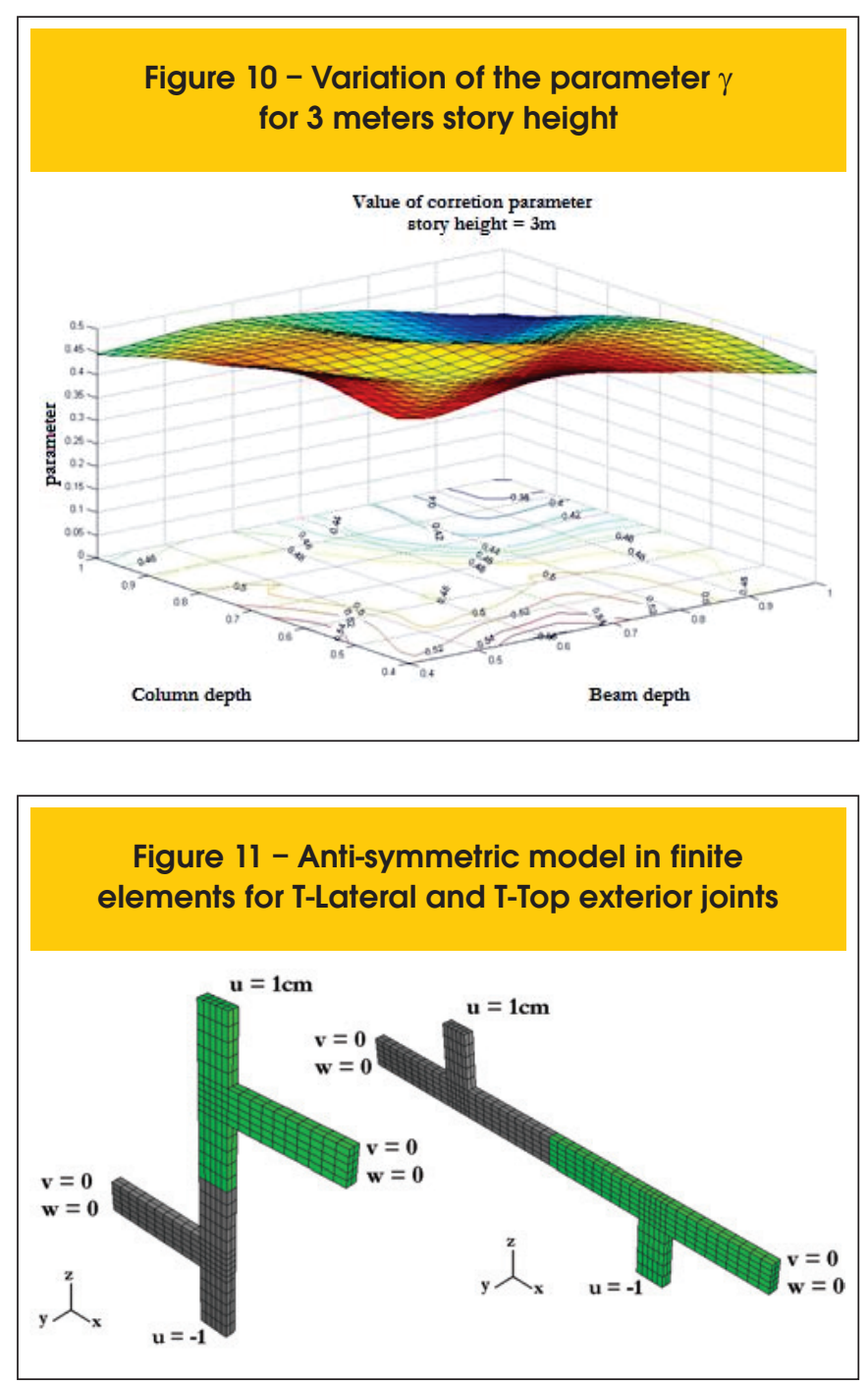

umns. Story heights of 3 and 4 meters were considered. For each height, values of $40,60,80$, and $100 \mathrm{~cm}$ were adopted for both beams and columns depths. Adopted values for the correction factor $\gamma$ for cross type interior joints, T-lateral and T-top joints, and L-type joints will be denoted by $\gamma_{C}, \gamma_{T}$ and $\gamma_{L}$, respectively.

\subsubsection{Cross type interior joints}

Initially a parametric study for the interior Cross-type joint is conducted. The boundary conditions applied to the three-dimensional model are the same as those used in the examples of Section 2. The adopted value of parameter $\gamma$ is obtained comparing results from the scissors and the finite elements models.

The first issue to be discussed is the appropriate value of the joint volume, $\nabla_{N}$, that should be adopted for joints with general width/depth ratios. Figure 9 shows the shear stress contours for two different joint geometries: square, and the one in which the height is twice its width. It can be readily noticed that the behavior changes substantially. To approximate the geometric effect,
Horowitz and Marques [9] suggests the following approach for the computation of the effective joint volume:

$$
\nabla_{N}=a \frac{(a+b)}{2} t
$$

Where $a$ and $b$ are the joint dimensions, with $a \leq b$, and $t$ is the joint thickness.

Figure 10 shows the surface that represents the variation of the computed correction parameter, $\gamma$, with the depths of beam and column sections, for a story height of $3 \mathrm{~m}$. From the analysis of the obtained results the value of the parameter $\gamma$ for cross-type joints, $\gamma_{C}$, was taken as 0,45 , which represents a value slightly below the average with a bias to larger flexibility. This is also representative for story height of $4 \mathrm{~m}$ as shown in Horowitz and Marques [9], where the authors detail extensive parametric study of the scissors model applied to complete interior joints.

\section{Figure 12 - Finite element anti-symmetric mode for L-type joints}

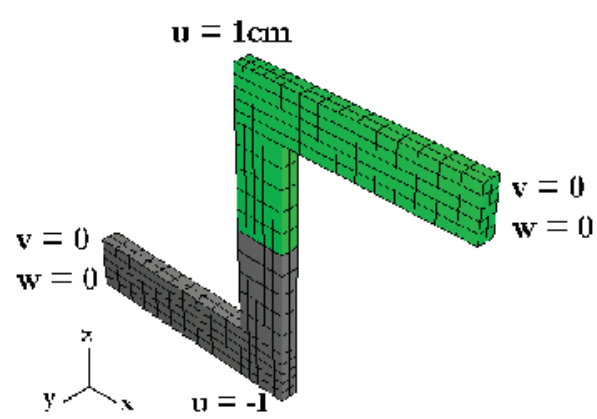

Figure 13 - Deformed configuration of the complete cross-type joint

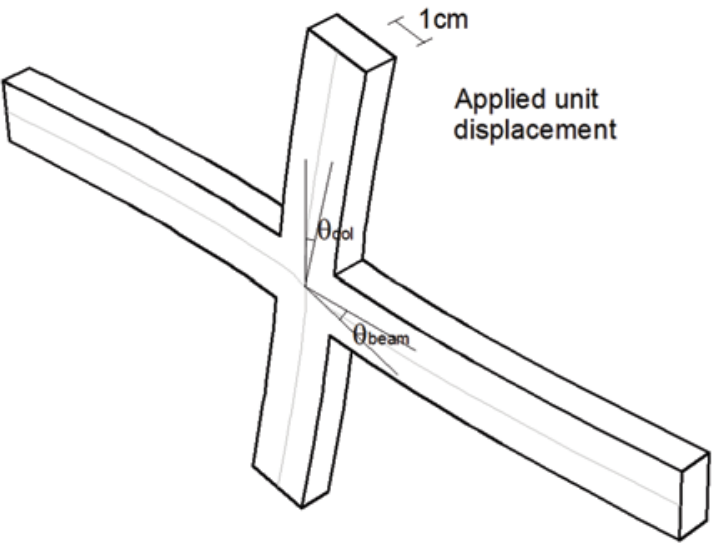




\subsubsection{Complete T-Lateral and T-Top exterior joints}

Consider now the T-Lateral and T-Top exterior joints. Typical three-dimensional finite elements models are shown in Figure 11 with the imposed boundary conditions, where $u, v$ and $w$ are translations along global axes $x, y$ and $z$, respectively. An anti-symmetric displacement field was applied in order to force a zero moment section at mid-height of the column and mid-span of the beams without resorting to multi-node artificial constraints.

Similarly to cross-type joints the correction factor, $\gamma_{T}$, for T-type joints, is evaluated as the result of a parametric study. The final adopted value is, $\gamma_{T}=0,3$, as reported by Horowitz and Marques [10], where the authors give a detailed analysis of the scissors model applied to complete T and L-type joints.

\subsubsection{Complete L-type exterior joints}

The previously used modeling techniques are also employed for L-type joints as shown in Figure 12.

As a result of the parametric study it was adopted, $\gamma_{L}=0,1$, as reported in Horowitz and Marques [10].

\section{Concentric joints}

\subsection{Modeling the flexibility of concentric joints}

Consider the beam/column joint shown in Figure 13 subjected to an arbitrary displacement at its top section. One has that the difference between the rotation of the beam, $\theta_{\text {beam }}$, and the rotation of the column, $\theta_{\text {col, }}$ is due to the shear distortion of the joint region, as discussed in Section 2.

Consider now the concentric cross-type joint, shown in Figure 14(a), subjected to a uniform displacement at its top section. The elastic restraint from strip $B-B$ ' is less effective than that offered by $A-A$ ' due to the column horizontal torsional deformations in the region of framing of the beams.

In order to take into account this phenomenon, we consider a torsional member embedded in the column as show in Figure 14(b). The additional flexibility of the joint is that resulting from the flexibility of the torsional member, similarly to the proposed $\mathrm{ACl}$ code [11] equivalent frame formulation provisions for the computation of column stiffness in flat slabs.

The differential rotation between the beam and the column, $\theta_{\text {conc }}$, is given by:

$$
\theta_{\text {conc }}=\frac{M}{K_{\text {conx }}}
$$

The value of $\theta_{\text {conc }}$ can be taken as the sum of the differential rotation of the column at the point of incidence of the beam, $\theta_{\mathrm{A}}$, and the average rotation of the torsional member inside the joint, $\theta$

As flexibility is the inverse of stiffness, and considering $\theta_{\mathrm{A}}$ as being that corresponding to a complete joint, one has that:

$$
\frac{1}{K_{\text {canc }}}=\frac{1}{K_{\text {complete }}}+\frac{1}{K_{\text {tor }}}
$$

The value of $K_{\text {complete }}$ was derived in Section 3.4 for the various types of joints. The term corresponding to the torsional stiffness is detailed below.

\section{Figure 14 - (a) Complete cross-type joint; (b) Cross-type with torsional member}

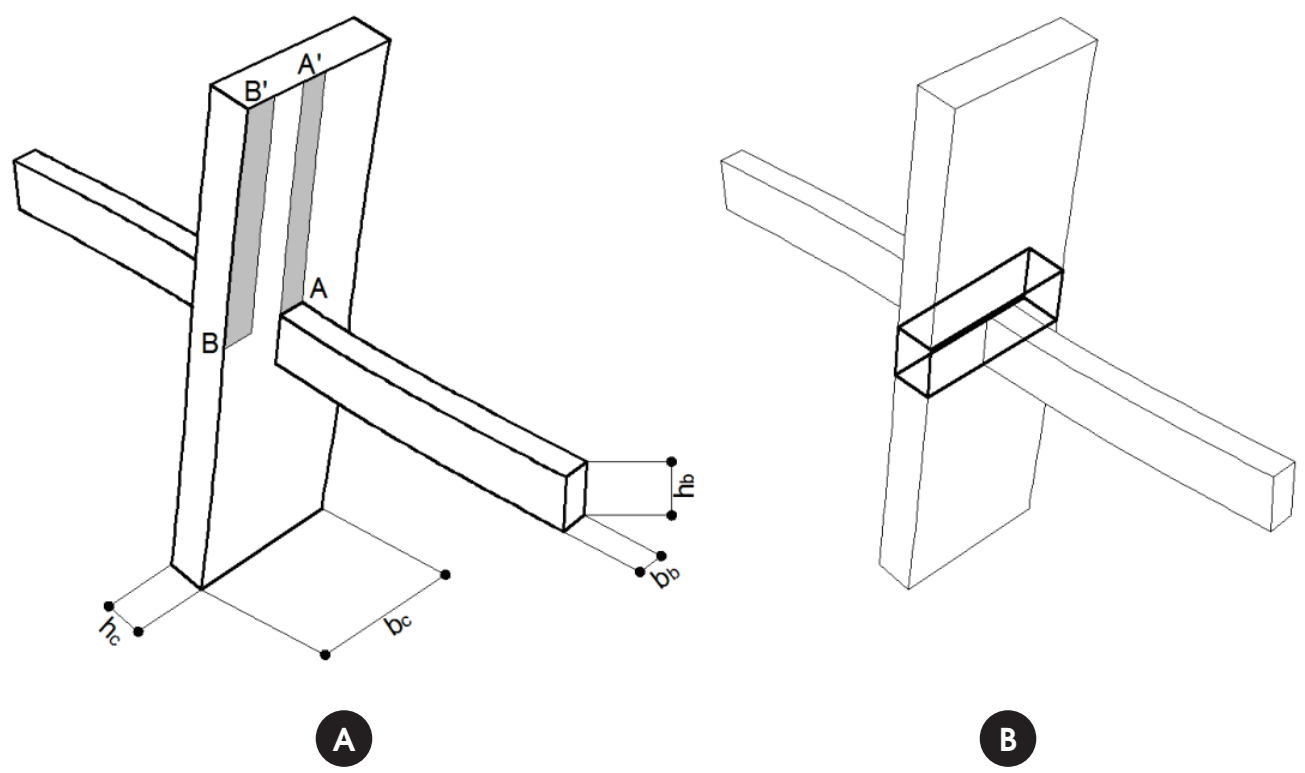




\subsubsection{Torsional stiffness}

Consider a column connected to a torsional member and subjected to a unit torsional moment, as shown in Figure 15(a). Assuming a linear distribution of moment per unit length and considering that the maximum value of the torsional moment at the center of joint is such as to provide a unit area under the diagram (see Figure 15(b)), it follows that the function that expresses the change of the applied moment to only one of the two arms of the torsion member, as shown in the discussion of the equivalent frame method in MacGregor's textbook [12], is:

$$
t(x)=\frac{4}{b_{C}^{2}} x
$$

where $b_{C}$ is the width of the column (see Figure 14(a)).

From the loading distribution one can obtain the torsional moment diagram $T(x)$ by integrating the function $t(x)$, as shown in Figure 15(c):

$$
T(x)=\int \frac{4}{b_{C}^{2}} x d x \quad \therefore \quad T(x)=\frac{2}{b_{C}^{2}} x^{2}
$$

Figure 15 - Side view of the joint showing the torsional member; (b) torsional moment applied to the member; (c) torsional moment diagram in the torsional member; (d) derivative of rotation along the member

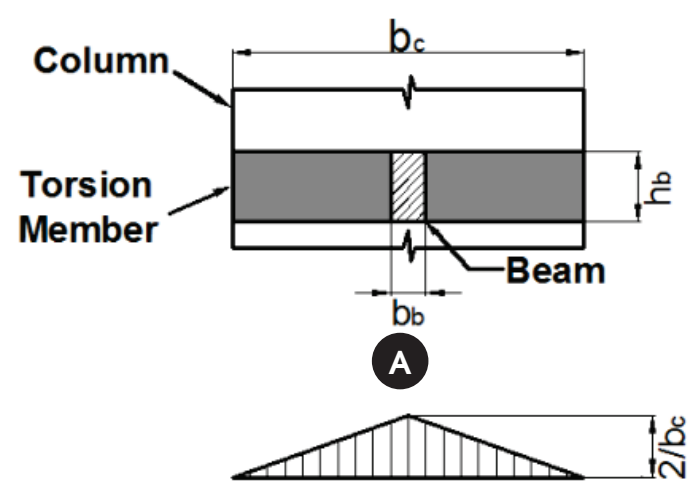

B

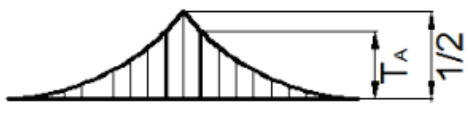

C

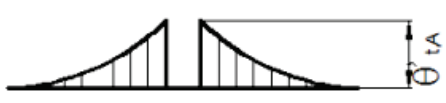

D
Function $T(x)$ expresses the variation of the torsional moment along the member.

From Figure 15(c) one has that the value of $T$ at the point of framing of the beam on the column, point A of strip A-A' in Figure 14(a), is given by:

$$
T_{A}=T\left(\frac{b_{C}}{2}-\frac{b_{B}}{2}\right)=\frac{1}{2}\left(2-\frac{b_{B}}{b_{C}}\right)^{2}
$$

Where $b_{B}$ is the width of the beams.

The value of the derivative of the rotation in each section along the torsional member with respect to $x$ is obtained by dividing the torsional moment at each section by CG, as shown in Figure 15(d), is given by:

$$
\frac{d \theta(x)}{d x}=\frac{2}{C G b_{C}^{2}} x^{2}
$$

Where $G$ is the transverse modulus of elasticity of the material and $\mathrm{C}$ is the torsional constant used in the $\mathrm{ACl}$ code [11], given by:

$$
C=\left[\left(1-0,63 \frac{x}{y}\right) \frac{x^{3} y}{3}\right]
$$

Where $\mathrm{x}$ is the least value between $b_{C}$ and $b_{B}$, and $\mathrm{y}$ being the largest.

The rotation at the end of the member is the integral of the derivative of the rotation along the member, and is given by:

$$
\theta_{t, \text { md }}=\int_{0}^{\frac{b_{C}}{2} \frac{b_{s}}{2}} \frac{2}{C G b_{C}^{2}} x^{2} d x \quad \therefore \theta_{t, e \text { end }}=\frac{b_{C}}{12 C G}\left(1-\frac{b_{B}}{b_{C}}\right)^{3}
$$

Poisson's ratio for concrete is taken as 0,2 , thus the transverse modulus of elasticity is $0,42 E$. Substituting $G$ for $E / 2$, as suggested in the $\mathrm{ACl}$ code [11], and assuming that the average rotation of the member is one-third of the rotation at its end, one concludes that:

$$
\theta_{t, \text { average }}=\frac{b_{C}\left(1-\frac{\left.b_{B} / b_{C}\right)^{3}}{18 E C}\right.}{18 E}
$$

Torsional stiffness $K_{\text {tor }}$ is the inverse of flexibility and therefore is given by:

$$
K_{t o r}=\frac{18 E C}{b_{C}\left(1-b_{B} b_{C}\right)^{3}}
$$




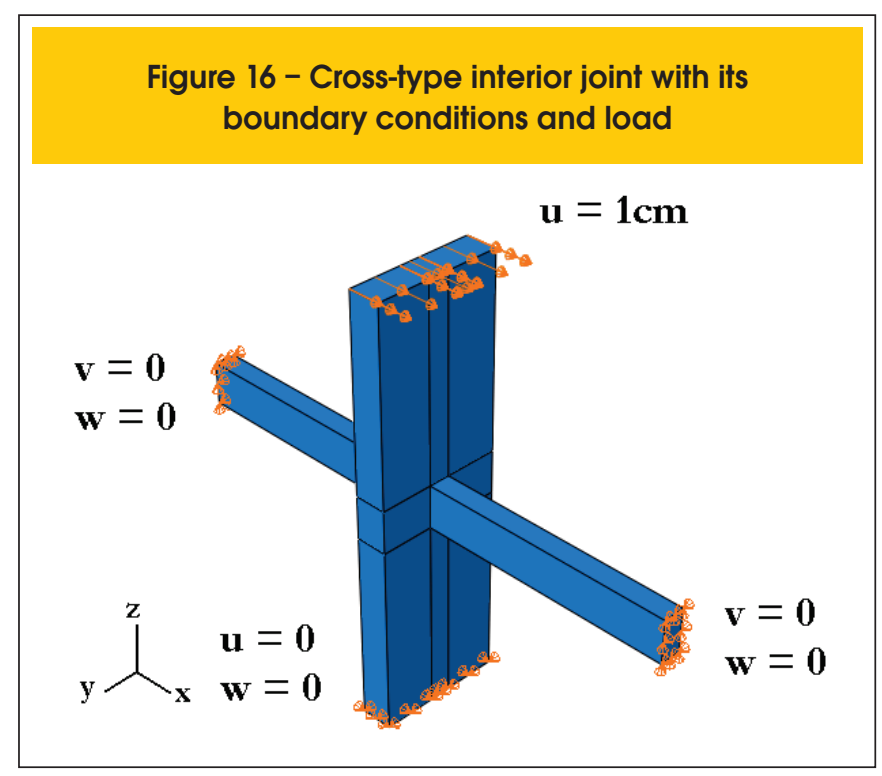

\subsection{Parametric study of concentric joints}

Substituting the values of $K_{\text {complete }}$ and $K_{\text {tor }}$ in Equation (11) one arrives at the following expression:

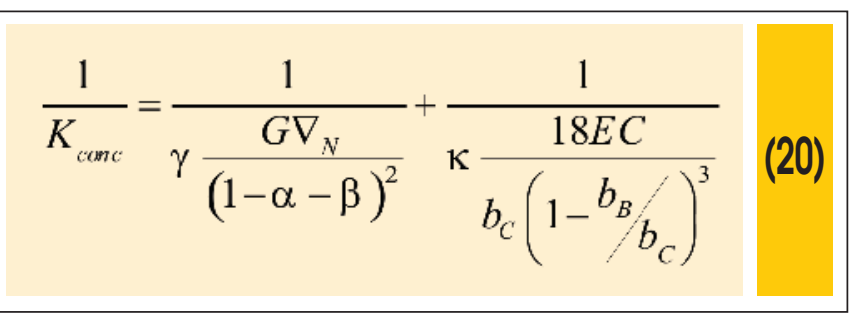

Where $\gamma$ and $\kappa$ are correction factors. The values of $\gamma$ were obtained for each type of joint in Sections 3.4.1 through 3.4.3. In the following sections the values for $\kappa$ are obtained from a parametric study, similar to the ones conducted for complete type joints.

\subsubsection{Concentric cross-type interior joints}

In this new parametric study subassemblages are analyzed with story heights of 3 and 4 meters, beams with cross-section of $20 \times 40,20 \times 60,30 \times 40$, and $30 \times 60 \mathrm{~cm}$ and columns with crosssection heights of 20,30 and $40 \mathrm{~cm}$ and widths of $40,60,80,100$, $120,140,160,180$ and $200 \mathrm{~cm}$. As in the modeling conducted for complete joints, the horizontal translation in the bottom of the column and the vertical translation at the ends of the beams were prevented. The reaction force resulting from an imposed displacement of $1 \mathrm{~cm}$ applied at the top of the column of the finite element model is computed for each subassemblage. Figure 16 shows a crosstype joint with applied boundary conditions and external loading. As seen in Section 3.4.1, the value of correction parameter for complete cross-type joints is $\gamma_{c}=0,45$. Using $\kappa=1$ in Equation (20) to compute the spring stiffness of the scissors model results in differences of less than $5 \%$ when comparing with the finite element analyses. Therefore the correction factor of the torsional term for concentric cross-type interior joints is taken as, $\kappa_{C}=1$.

\subsubsection{Concentric T-Lateral exterior joints}

Consider now T-lateral type joints. The three-dimensional finite element models are shown in Figure 17(a). Using $\gamma_{T}=0,3$ and adopting $\kappa_{T-L a t}=1$, the maximum difference obtained with the proposed model when compared with the finite elements results is in the order of $6 \%$.

\subsubsection{Concentric T-Top exterior joints}

The modeling of the T-Top joint is conducted in the same way as for the T-lateral exterior joints, as can be seen in Figure 17(b). If one uses $\gamma_{T}=0,3$ and $\kappa=1$ in Equation (20) for the computation of the torsional stiffness, the resulting frame model is $20 \%$ stiffer than the finite element model. Therefore based on the parametric study

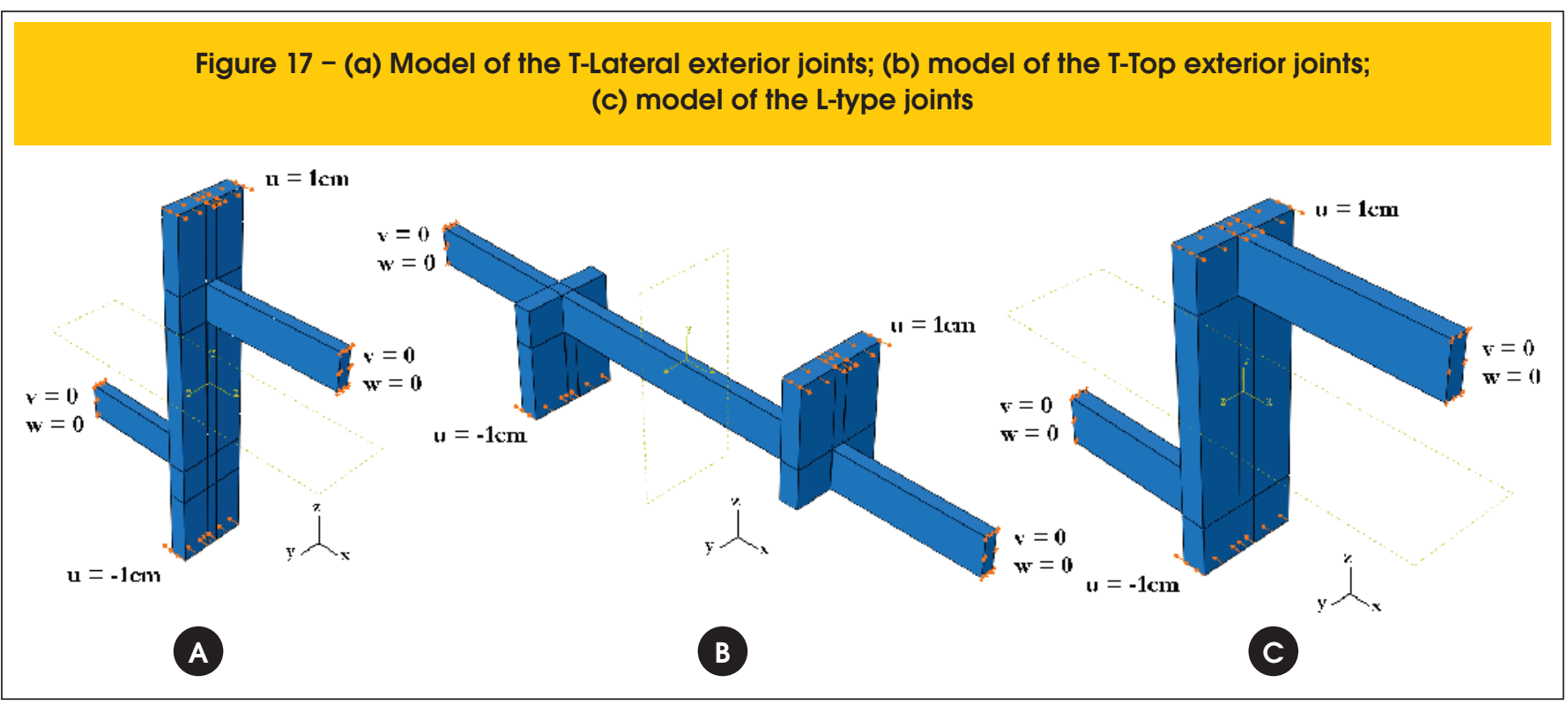




\section{Figure 18 - Experimental setup for the cross-type joint (13)}

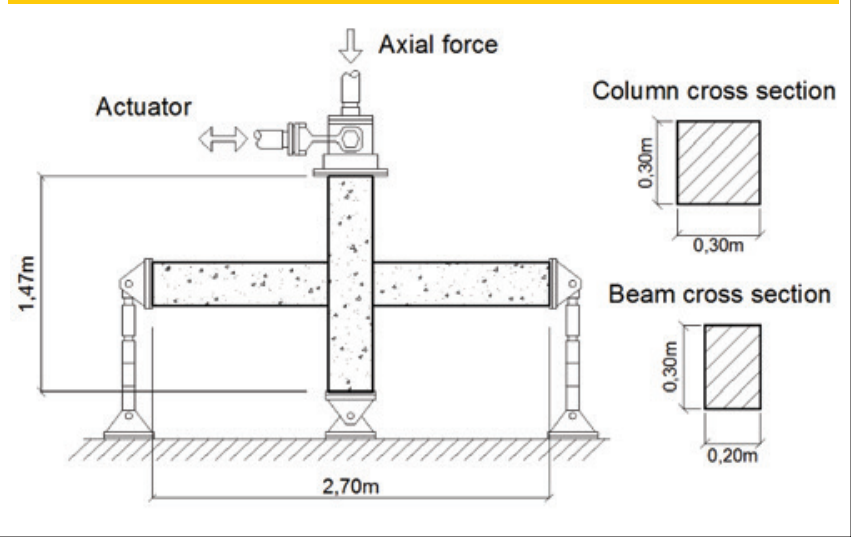

it was adopted $\kappa_{T-\text { Top }}=0,5$ which results in a maximum difference of $10 \%$ with respect to finite element analyses.

\subsubsection{Concentric L-type joints}

Figure 17 (c) shows the three-dimensional model used for L-type joints with its applied boundary conditions. The modeling of L-type joints using $\gamma_{L}=0,1$ and $\kappa=1$, as in the case of T-Top exterior joints, presents significant differences with respect to finite element results, in the order of $40 \%$.

As a result of the conducted parametric study it is adopted $\kappa_{L}=$ 0,25 . The use of this correction parameter decreased the maximum misfit in stiffness of the results from the two models to $20 \%$. Since this type of joint is less frequent in the structures of buildings no significant loss of precision in global flexibility is expected.

\section{Results and discussion}

\subsection{Comparison with experimental results}

In order to calibrate the modeling of joint flexibility with real cases of structural buildings we initially conduct a comparison of the proposed scissors model prediction with experimental results found in the literature.

Table 1 - Comparison of actuator force with numerical results - Cross-Type interior joint

\begin{tabular}{|ccc|}
\hline Model & \multicolumn{2}{c|}{ Shear Force, $\mathbf{V}_{\mathrm{c}}(\mathbf{k N})$} \\
\hline & Theoretical & Experimental \\
\hline $\begin{array}{c}\text { Finite Elements } \\
\text { Unadjusted rigid link }\end{array}$ & 35,5 & 21 \\
Scissor's Model with & 43,1 & 21 \\
uncracked bars & 36,1 & 21 \\
$\begin{array}{c}\text { Scissor's Model with } \\
\text { cracked bars }\end{array}$ & 21,2 & 21 \\
\hline
\end{tabular}

\subsubsection{Cross-type interior joints}

Consider the experimental arrangement shown in Figure 18 developed by Shiohara et al [13]. The columns have cross-section of $30 \times 30 \mathrm{~cm}$, the beams cross section is $30 \times 20 \mathrm{~cm}$, the height of the column is $1,47 \mathrm{~m}$ and the length of the beam is $2,7 \mathrm{~m}$. NBR-6118 code [2] recommends maximum lateral displacement of $\mathrm{H} / 850$ for the wind action, representing a displacement of $0,12 \%$ of the story height. Using the experimental results of shear versus displacement, one reaches the conclusion that for a $0,12 \%$ drift, the corresponding horizontal force is $21 \mathrm{kN}$. The concrete strength is equal to $28 \mathrm{MPa}$. The concentric scissors model is constructed with the following parameters: $E=0,85 \times 5600(28)^{0,5}=2,52 \times 10^{4} \mathrm{MPa} ; \mathrm{G}=1,05 \times 10^{4} \mathrm{MPa}$; $\alpha=0,111 ; \quad \beta=0,204 ; \quad \nabla_{N}=2,7 \times 10^{2} \quad \mathrm{~m}^{3} ; \quad K_{\text {comp }}=272 \quad \mathrm{MN}-\mathrm{m} / \mathrm{rad}$; $K_{\text {tor }}=40783 \mathrm{MN}-\mathrm{m} / \mathrm{rad} ; K_{\text {conc }}=270 \mathrm{MN}-\mathrm{m} / \mathrm{rad}$.

The following four structural models are considered for comparison purposes:

- Finite Elements.

- Bars with unadjusted rigid links.

Scissors model with uncracked bars.

Scissors model with effective moments of inertia according to the NBR6118 code: $I_{\text {cole },}=0,8 I_{\text {col }} ; I_{\text {beam e }}=0,5 I_{\text {beam }} ; K_{N T \text {, e }}=0,8 K_{N T}$. Where $I_{\text {col,e }}$ and $I_{\text {beam,e }}$ are the effective moments of inertia of columns and beams to be used in the structural analysis to approximately take cracking into account. The effective value of the torsional spring stiffness, $K_{N T, e}$, is computed using the column reduction factor.

The obtained results from the four models are shown in the Table 1. Results in Table 1 indicate that the scissors model with uncracked bars, reproduced quite accurately the results of the finite element model, demonstrating the suitability of the parametric adjustment. In order to reproduce the experimental results the gross moment of inertia of the members must be reduced to take cracking into account. The unadjusted rigid link model is twice as stiff as the scissors model with effective moments of inertia.

\subsubsection{T-Lateral exterior joint}

From the experimental specimen of the T-Lateral exterior joint shown in Figure 19 [14], comparisons were conducted with the proposed model. The specimen consists of columns $2,70 \mathrm{~m}$ high and a beam with span of $2,15 \mathrm{~m}$. The column has a cross-section

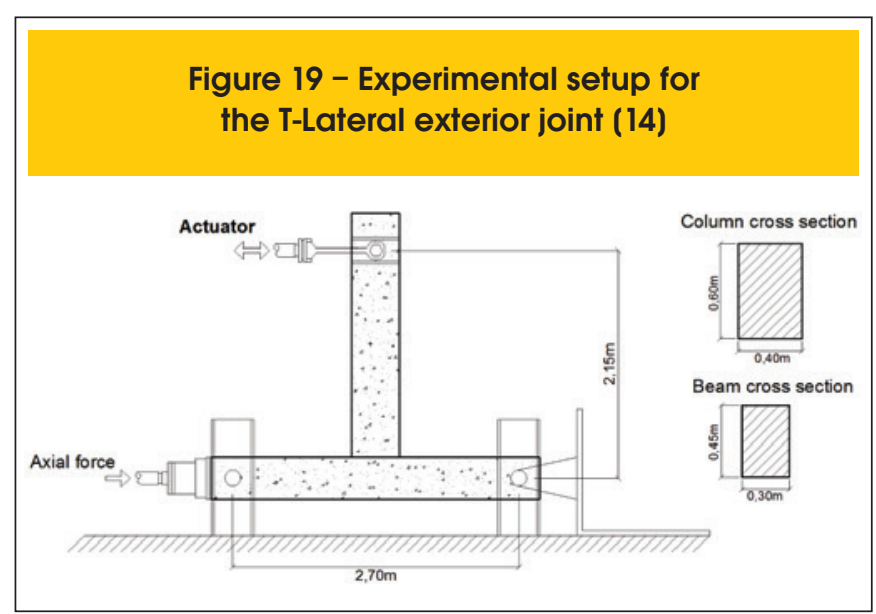


Table 2 - Comparison of actuator force with numerical results - T-Lateral exterior joint

\begin{tabular}{|ccc|}
\hline \multirow{2}{*}{ Model } & \multicolumn{2}{c|}{ Shear Force, $\mathrm{V}_{\mathrm{c}}(\mathrm{kN})$} \\
& Theoretical & Experimental \\
\hline $\begin{array}{c}\text { Finite Elements } \\
\text { Unadjusted rigid link }\end{array}$ & 96,9 & 48,3 \\
$\begin{array}{c}\text { Scissor's Model with } \\
\text { uncracked bars }\end{array}$ & 88,7 & 48,3 \\
$\begin{array}{c}\text { Scissor's Model with } \\
\text { cracked bars }\end{array}$ & 50,2 & 48,3 \\
\hline
\end{tabular}

of $40 \times 60 \mathrm{~cm}$ and the beams $45 \times 30 \mathrm{~cm}$, the concrete strength is $29,5 \mathrm{MPa}$. In the experimental arrangement the columns ends are hinged in order to simulate the inflection points in a real building frame and cyclic loading is applied at the end of the beam. Using the experimental data provided by the senior author of Reference [14], it was found that for a displacement of $5,28 \mathrm{~mm}$, corresponding to a $0,25 \%$ drift, the applied force is $48,3 \mathrm{kN}$.

The concentric scissors model is constructed with the following parameters: $E=0,85 \times 5600(29,5)^{0,5}=2,58 \times 10^{4} \mathrm{MPa} ; \mathrm{G}=1,08 \times 10^{4} \mathrm{MPa}$; $\alpha=0,093 ; \beta=0,167 ; \nabla_{N}=0,102 \mathrm{~m}^{3} ; K_{\text {comp }}=787 \mathrm{MN}-\mathrm{m} / \mathrm{rad} ; K_{\text {tor }}=26209$ $\mathrm{MN}-\mathrm{m} / \mathrm{rad} ; K_{\text {conc }}=587 \mathrm{MN}-\mathrm{m} / \mathrm{rad}$.

The same four kind of models used in the previous section are compared in Table 2. The scissors model with uncracked bars presents a $8,5 \%$ error when compared to the finite element model. Considering the cracking of the model based on the reduction factors of the gross moment of inertia of the sections recommended by the Brazilian code, NBR 6118 [2], the prediction error for the proposed model with respect to the experimental results is $3,9 \%$. Once again the unadjusted rigid links proved to be twice as stiff as the cracked scissors model.

\subsubsection{L-type joint}

In the case of concentric L-type exterior joints, the proposed model was compared with experimental results obtained by Angelakos[15]. Figure 20 shows a schematic representation of the experimental arrangement. The specimen has a span of $1,325 \mathrm{~m}$ and
Figure 20 - Experimental setup for L-type joint (15)

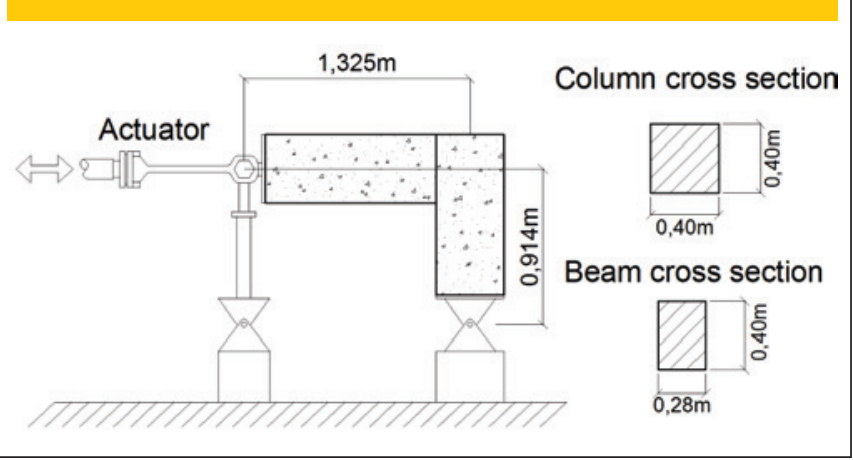

height of $0,914 \mathrm{~m}$. The cross-section of the beam is $28 \mathrm{~cm}$ by $40 \mathrm{~cm}$ and that of the column is $40 \mathrm{~cm}$ by $40 \mathrm{~cm}$. It was used a $1,83 \mathrm{~mm}$ displacement representing the magnitude of the serviceability limit imposed by the NBR 6118 code [2]. The concrete strength is $31,7 \mathrm{MPa}$. The concentric scissors model uses the following parameters: $E=0,85 \times 5600(31,7)^{0,5}=2,68 \times 10^{4} \mathrm{MPa} ; \mathrm{G}=1,12 \times 10^{4} \mathrm{MPa}$; $\alpha=0,152 ; \beta=0,219 ; \nabla_{N}=0,064 \mathrm{~m}^{3} ; K_{\text {comp }}=180 \mathrm{MN}-\mathrm{m} / \mathrm{rad} ; K_{\text {tor }}=35275$ $\mathrm{MN}-\mathrm{m} / \mathrm{rad} ; K_{\text {conc }}=179 \mathrm{MN}-\mathrm{m} / \mathrm{rad}$.

The same four models previously used are compared in Table 3. Another feature is to be highlighted. Different experimental results were obtained for displacements that open or close the joint. This demonstrates the importance of the contribution of the reinforcement slip. Once more it can be seen the small difference, around $4 \%$, between the proposed scissors model and the result of the finite element analysis. When the cracked scissors model is compared with the average of the experimental results, it is observed that the difference is only $2,9 \%$.

\subsection{Multi-story frames}

In order to assess the accuracy of the proposed simplified joint model, six multi-story frames without slabs were analyzed and comparisons made between unadjusted rigid links, proposed scissors model and the finite elements model. In Figure 21 it can be observed typical geometry of the frames where $L$ is the bay length, $\mathrm{H}$ is the story height, $n_{\text {bay }}$ is the number of bays and $n_{\text {sto }}$ the number of stories.

Table 3 - Comparison of actuator force with numerical results - L-type joint

\begin{tabular}{|c|c|c|c|}
\hline \multirow{3}{*}{ Model } & \multirow{3}{*}{ Theoretical } & \multicolumn{2}{|c|}{ Shear Force, $\mathrm{V}_{\mathrm{c}}(\mathrm{kN})$} \\
\hline & & \multicolumn{2}{|c|}{ Experimental } \\
\hline & & Opening & Closing \\
\hline Finite Elements & 12,65 & 10 & 6,7 \\
\hline Unadjusted rigid link & 19,74 & 10 & 6,7 \\
\hline $\begin{array}{l}\text { Scissor's Model with } \\
\text { uncracked bars }\end{array}$ & 13,1 & 10 & 6,7 \\
\hline $\begin{array}{l}\text { Scissor's Model with } \\
\text { cracked bars }\end{array}$ & 8,59 & 10 & 6,7 \\
\hline
\end{tabular}




\section{Figure 21 - Schematic detail of the geometry and the loading applied to the frames}
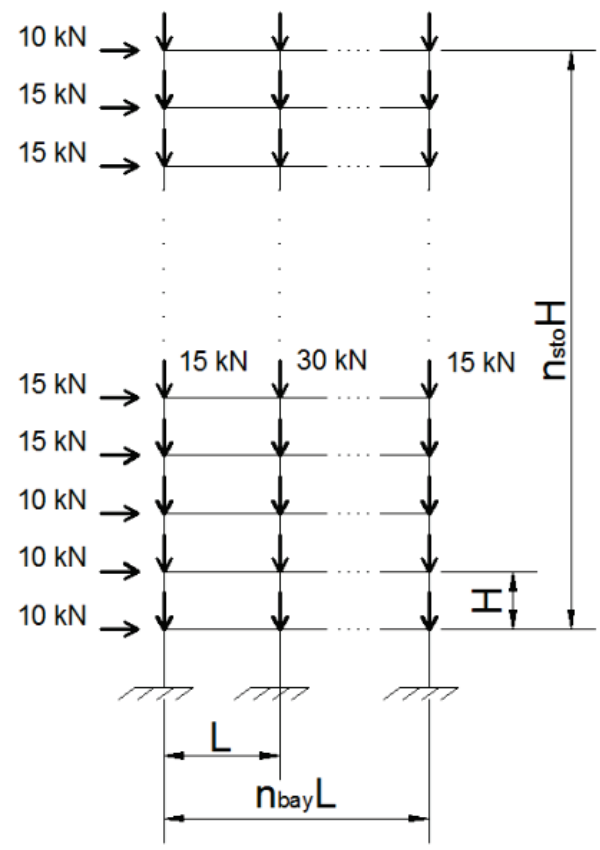

In all cases a $10 \mathrm{kN}$ lateral load was applied in the first three and the last floors while a $15 \mathrm{kN}$ load was applied to the intermediate remaining floors. The horizontal load was applied in the joints of the outer columns. In order to verify the effect of the geometric nonlinearity, a vertical load of $15 \mathrm{kN}$ is applied to the outer columns and $30 \mathrm{kN}$ to the inner columns at all stories. The load applied to the three-dimensional model of frame 1 can be seen in Figure 22. In the first two examples the frames contain complete joints only, while the remaining frames contain concentric type joints only. Table 4 summarizes the geometry of the frames adopted in the analyses.

In Table 5 second-order analysis results are presented, where the percentage difference for the displacement response of each model is computed with respect to the finite element model. It can be readily seen that the scissors model presents the best results when compared to the finite element model. The maximum percentage difference is $5 \%$, while for the model using unadjusted rigid links the difference increases to $16 \%$. The last two columns contain lateral displacements of the scissors model with cracked members and the percentage increase due to cracking. It can be seen that average amplification of displacements is $46,5 \%$ which has a significant impact on bending moments of beams and columns.

\section{Conclusions}

Beam/column joint flexibility in usual reinforced concrete building frames, disregarding the presence of slabs and transverse beams, contributes around $20 \%$ of the total lateral displacement. Therefore joint flexibility modeling is needed to check the excessive lateral displacement serviceability limit state as well as the global second order effects in ultimate limit states.

The NBR-6118 code [2] suggests the use of a rigid link model whose adjusted lengths are functions of the framing beam depths. Since joint flexibility stems from shear distortion, not bending inside the joint, this model may not always yield accurate results. An accurate yet simple scissors model, composed of bars and springs only, is proposed to take into account the flexibility of

\section{Figure 22 - Applied loads for frame model 1}

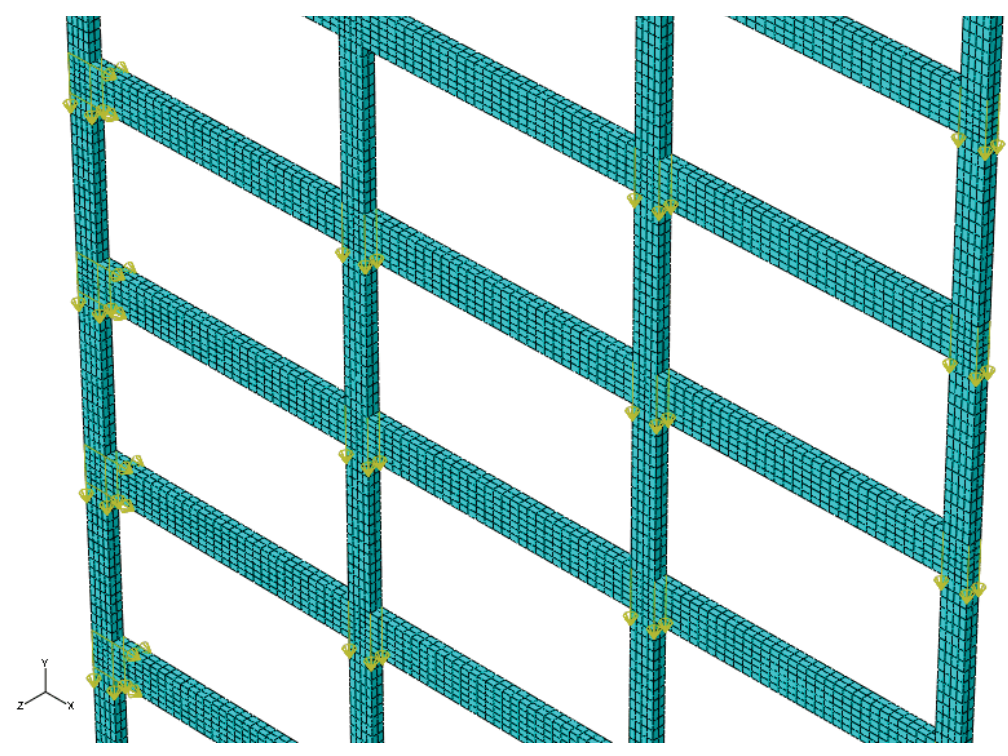




\section{Table 4 - Geometry of analyzed frames}

\begin{tabular}{|c|c|c|c|c|c|c|}
\hline \multicolumn{7}{|c|}{ Complete joints frames } \\
\hline Frames & $\mathrm{n}_{\text {bays }}$ & $L(m)$ & $\mathbf{n}_{\text {sto }}$ & $H(m)$ & Beam section $(\mathrm{cm})$ & Column section $(\mathrm{cm})$ \\
\hline 1 & 3 & 5 & 14 & 3 & $20 \times 60$ & $20 \times 40$ \\
\hline 2 & 1 & 6 & 14 & 3 & $20 \times 80$ & $20 \times 60$ \\
\hline \multicolumn{7}{|c|}{ Concentric joints frames } \\
\hline Frames & $\mathrm{n}_{\text {bays }}$ & $L(m)$ & $n_{\text {sto }}$ & $H(m)$ & Beam section $(\mathrm{cm})$ & Column section $(\mathrm{cm})$ \\
\hline 3 & 3 & 5,3 & 16 & 3 & $20 \times 60$ & $100 \times 30$ \\
\hline 4 & 3 & 5 & 16 & 3 & $15 \times 70$ & $130 \times 30$ \\
\hline 5 & 2 & 4 & 16 & 3 & $20 \times 60$ & $100 \times 20$ \\
\hline 6 & 1 & 5 & 20 & 3 & $20 \times 60$ & $100 \times 30$ \\
\hline
\end{tabular}

beam/column joints including the usual case of column sections wider than framing beam sections. Simple expressions for spring stiffnesses are obtained from mechanical models affected by correction factors whose values are determined from extensive parametric studies.

Comparative studies with experimental results demonstrate that the proposed model has adequate accuracy for design purposes if member stiffnesses are reduced according to the NBR- 6118 code [2] factors in order to take cracking into account. Maximum difference of $5 \%$ in displacements was observed between the proposed approximate scissors model and three-dimensional second order finite element analyses of six building plane frames.

\section{Acknowledgements}

The authors wish to recognize CAPES for financial support and Professor Hunk-Jen Lee for providing his experimental data.

\section{References}

[01] SHIN, M.; LAFAVE, J. M. Modeling of joint shear deformation contributions in RC beam-column connections to overall frame behavior. Structural Engineering and Mechanics, v.18, n.5, 2004; pp.645-669.
[02] ASSOCIAÇÃO BRASILEIRA DE NORMAS TÉCNICAS. Projeto de estruturas de concreto - Procedimento. NBR 6118, Rio de Janeiro, 2007.

[03] ABAQUS, User's Manual, version 6.3, Hibbitt, Karlsson\& Sorensen, Inc, Pawtucket, RI, 2002.

[04] ABAQUS, Getting Started with ABAQUS/Standard, version 6.3, Hibbitt, Karlsson\& Sorensen, Inc, Pawtucket, RI, 2002.

[05] CHARNEY, F. A.; DOWNS, W. M. Modeling procedures for panel zone deformations in moment resisting frames, EECS/AISC Workshop on Connections in Steel structures, Amsterdam, 2004..

[06] HOROWITZ, B.; MARQUES, S. J. P. J. Modelação da flexibilidade de nós internos de pórtico em concreto armado. In: CMNE/CILAMCE, 2007, Porto-Portugal.

[07] BIRELY, A. C.; LOWES, L. N.; LEHMAN, D. E. Linear analysis of concrete frames considering joint flexibility, ACI Structural Journal, V. 109, No. 3, May-June 2012, pp. 381-391.

[08] KRAWINKLER, H.; MOHASSEB, S. Effects of panel zone deformations on seismic response, J. Constr. Steel Res., V. 8, 1987, pp. 233-250.

[09] HOROWITZ, B.; MARQUES, S. J. P. J. Efeito da seção do pilar na flexibilidade de nós internos de pórtico em concreto armado. In: $49^{\circ}$ Congresso

\section{Table 5 - Results os second order analyses}

\begin{tabular}{|cccccccc|}
\hline Frames & $\begin{array}{c}\text { Finite element } \\
\text { Drift (cm) }\end{array}$ & \multicolumn{2}{c}{$\begin{array}{c}\text { Unadjusted rigid links } \\
\text { Drift (cm) }\end{array}$} & $\begin{array}{c}\text { Error }(\%) \\
\text { uncracked bars } \\
\text { Drift (cm) }\end{array}$ & $\begin{array}{c}\text { Error }(\%) \\
\text { Scissor's model } \\
\text { cracked bars }\end{array}$ \\
\hline 1 & 6,23 & 5,26 & 15,5 & 6,52 & 4,6 & 9,24 & 41,7 \\
2 & 9,12 & 8,23 & 9,8 & 9,34 & 2,4 & 12,34 & 32,1 \\
3 & 5,36 & 4,64 & 13,4 & 5,32 & 0,7 & 8,52 & 60,2 \\
4 & 4,23 & 3,56 & 15,8 & 4,11 & 2,8 & 6,60 & 60,6 \\
5 & 13,84 & 12,11 & 12,5 & 14,03 & 1,4 & 19,38 & 38,1 \\
6 & 29,12 & 27,07 & 7,0 & 29,50 & 1,3 & 43,08 & 46,0 \\
\hline
\end{tabular}


Brasileiro do Concreto, IBRACON-CBC, 2007,

Bento Gonçalves, v.1, 2007.

[10] HOROWITZ, B.; MARQUES, S. J. P. J. Modelação

da flexibilidade de nós de pórtico em concreto armado com peças de mesma largura. In: $50^{\circ}$ Congresso

Brasileiro do Concreto, IBRACON-CBC, 2008,

Salvador - Brasil, v.1, 2008.

[11] ACl Committee 318, Building Code Requirements for Structural Concrete (ACl 318-08) and Commentary, American Concrete Institute, Farmington Hills, MI, 2008.

[12] MACGREGOR, J., Reinforced Concrete: Mechanics and Design, Prentice Hall, 3ed, 1997.

[13] Shiohara, H., Zaid, S. e Otani, S., Test of an Innovative Reinforcing Detail for High Performance R/C Interior Beam-Column Connection Subjected to Seismic Action, Proceedings of the Third International Conference on Concrete under Sever Conditions, Vancouver, 2001, pp. 739-746.

[14] LEE, H. J., YU, S. Y., Cyclic Response of Exterior Beam-Column Joints with Different Anchorage Methods, ACI Structural Journal, v.106, n.3, 2009; p.329-339.

[15] ANGELAKOS, B., The Behavior of Reinforced Concrete Knee Joints Under Earthquake Loads. Toronto, 1999, Thesis (Doctor of Philosophy) Department of Civil Engineering, University of Toronto. 